\title{
LAS POLÍTICAS E INTERVENCIONES SOCIALES. Algunas CONSIDERACIONES ÉTICAS.
}

\author{
THE SOCIAL INTERVENTIONS AND POLICIES. SOME ETHICAL CONSIDERATIONS
}

Por: Liliana Pérez Mendoza*

*LILIANA PÉREZ

MENDOZA

Trabajadora social (Universi-

dad de Cartagena. Magíster

en Trabajo Social (Pontificia

Universidad Católica de Chi-

le). Docente-investigadora

de la Universidad de Carta-

gena (Colombia). Miembro

del grupo de investigación:

Cultura, Ciudadanía y Poder

en Contextos Locales de la

Universidad de Cartagena,

reconocido en Categoría C

por Colciencias. E-mail: lpe-

rezm2@unicartagena.edu.co

/lperez1@puc.cl

Artículo Recibido: Abril 30 de 2010. Artículo Aprobado: Julio 15 de 2010. Páginas: 24-38

\section{RESUMEN:}

Hoy por hoy, se asume que los objetivos de las políticas sociales han de orientarse hacia la restauración de la ciudadanía a partir del acceso a derechos sociales y cívicos de los sujetos y la dinamización del vínculo o tejido social, que implica relacionar a las personas con otras y con las instituciones, siguiendo planteamientos como los de Cristina De Robertis (2003: 15). Por lo anterior, puede decirse que tales políticas deben potenciar esencialmente ciudadanos sujetos de derechos y una sociedad democrática, participativa, corresponsable, pero al mismo tiempo, solidaria; con vínculos sociales más estrechos, a fin de alcanzar una mayor justicia y equilibrio social, como principios éticos para la convivencia pacífica en las diferentes realidades socio-culturales.

Palabras clave: Política social, intervención social, ciudadanía, solidaridad, ética.

\section{ABSTRACT}

Today, it is assume that the objectives of social policies should be lead to the restoration of the citizen, starting in the access of social and civics rights of the subjects and the dynamic of the social bond or social weave, that involves relating people with others and other institutions, following statements made such as the one from Cristina De Robertis (2003:15). Therefore, it can be said that such policies should empower citizens subjects rights and a democratic, participatory, co-responsible society, but at the same time, with solidarity and a closer social bonds, in order to achieve greater social justice and balance, as ethical principles for the peaceful coexistence of different socio-cultural realities.

Keywords: Social policy, social intervention, citizenship, solidarity, ethic.

\section{Introducción:}

T mpulsar múltiples caminos y condiciones, espacios, encuentros dirigidos a la auto-constitución particular de sujetos ciudadanos capaces de poner en la agenda pública la exigencia de sus derechos sociales y de actuar en consecuencia, de manera corresponsable hacia el ejercicio de estos, es desde el ámbito de las políticas e intervenciones sociales un imperativo en la actualidad; por cuanto, como señala Autès, la verdadera inserción de los sujetos a la sociedad viene dada cuando desde la política e intervención social, se contribuye a "crear la demanda", más que la oferta (que hoy en día siempre 


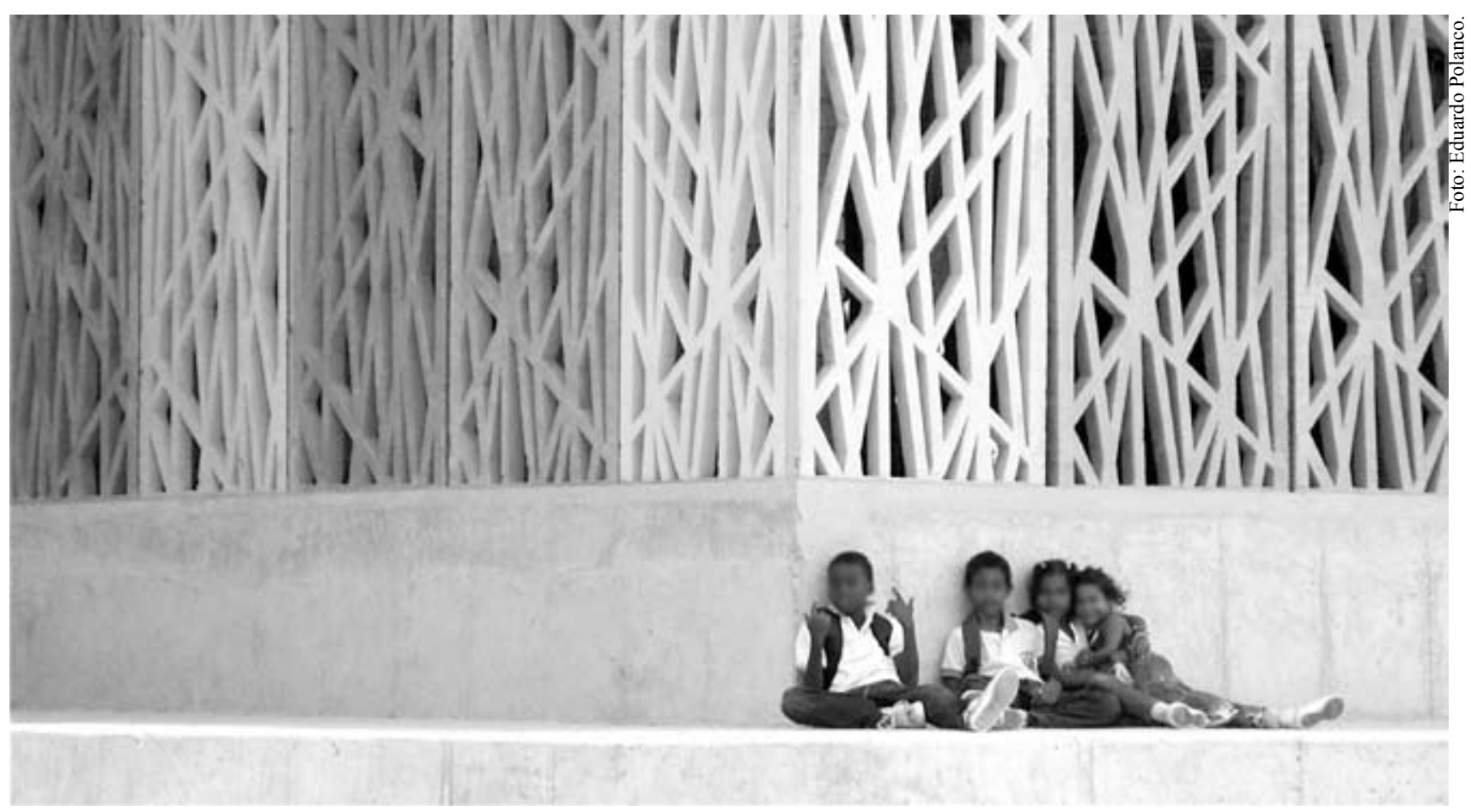

“Fin de jornada escolar". Cartagena 2011.

es precaria); para ello será necesario, según el autor, "recrear espacios para la comunicación, hacer cosas colectivas, volver a poner a la gente en escenas públicas. La inserción puede ser un itinerario, pero también una ocasión para crear espacios públicos" (2004: 37). De esta manera, el lazo social también se fortalece en la medida en que la política social se vuelca sobre el potenciamiento de la capacidad de expresión, de volver a la palabra, de hacerse oír de los actores a quienes se ha llamado "vulnerables", lo cual deviene en un accionar más comprometido con la sociedad.

\section{Un marco ético posible...}

El impulso del diálogo como mecanismo para realizar acciones sociales es un mecanismo que resulta válido para llegar a este punto. Por ello, retomar el planteamiento habermasiano de una ética discursiva, que parte de las que llama "grandes vergüenzas político-morales" que afectan a la sociedad tales como el hambre, la miseria, la tortura, la violación de la dignidad humana en los "estados de no-derecho, el desempleo, la inequitativa distribución de las riquezas, el riesgo de autodestrucción del armamento atómico, aunque puede resultar para algunos decepcionante o inaplicable, puede representar también, "un aguijón" (1991: 129-130).

Desde esta consideración, el diálogo se constituye en un procedimiento 
ético, que permite "ofrecer" respuestas contundentes a tales situaciones, en el escenario de las políticas e intervenciones sociales. Es más, si tal accionar social renunciase a un carácter ético, aún el discurso sería una posibilidad, porque las sociedades actuales son realidades producidas y mantenidas en las estructuras de la comunicación humana.

Según esta perspectiva, se trataría de asumir un accionar que reconozca y respete a cada otro como igual, como legítimo "otro", en el diálogo, con la intención de integrar colectividades, en las que no solamente se han fragmentado sus lazos sociales y comunicativos, sino que también el individualismo se ha fortalecido resquebrajando las esencias solidarias. Por ello, hoy las políticas e intervenciones sociales han de ser contextualizadas y complejizadas según esta realidad.

\section{Desde donde impulsar el carácter ético dialógico de las políticas e intervenciones sociales}

Se trata entonces, de que las instituciones del Estado, la empresa privada y las $\mathrm{ONG}^{\prime} \mathrm{s}$ orientadas hacia estas políticas, propicien la participación, desde el diseño e implementación, de manera discursiva y activa, no sólo de los destinatarios de las mismas, sino también de los agentes sociales que las ejecutan y evalúan; pues una política e intervención social que se precie de ser contemporánea, ha de fomentar la ciudadanía de los sujetos que a ella se vinculan, y en este caso, los profesionales también son participantes de la misma. Estos, al igual que los sujetos a quienes se dirigen, deben tener libertad para esgrimir un "si" o un "no" libre de coacciones, frente al acercamiento o desencanto que producen en la población "las estrategias" vinculantes a los programas o proyectos sociales que la instrumentalizan.

Cobra singular importancia para los entes encargados de implementarlas, el reconocimiento de los significados que estas políticas tienen para los profesionales que las ejecutan, las contradicciones que encuentran entre los discursos y prácticas de las instituciones, las propias y las de los sujetos a quienes se dirigen las mismas, los procesos que impulsan de manera espontánea para una mayor autonomía y ciudadanía de los sujetos con quienes intervienen, y el conocimiento de hasta dónde ellos mismos tienen también la posibilidad de ser considerados ciudadanos, sujetos de derechos y deberes en la implementación de las mismas. 
Esta línea de acción permite la confrontación de subjetividades e intersubjetividades, para determinar las condiciones ideales de una intervención de lo social que se cifre, entre otras cosas, en lo positivo, lo que es digno y satisfactorio alcanzar y no, sobre lo que no se desea lograr. Para ello se requiere pensar la política e intervención social "no más como simple práctica, sino como una gramática propositiva que se gesta en lo público, que coloca cosas nuevas en el mundo, que promueve ciudadanías, que incentiva proyectos, que hace germinar diálogos participativos, que se orienta en pos de un desarrollo más humano, donde a nadie le sea negada la realidad de lo posible" (Matus, 2005: 61).

Esto implica que entes y agentes revisen y fundamenten marcos ético-teóricos referenciales, estrategias, procedimientos, técnicas y apuestas investigativas sobre el contexto en las políticas e intervenciones sociales, frente a las conceptualizaciones y prácticas de los sujetos participantes, argumentadas discursivamente y entendidas como un derecho, que se va a traducir en una forma consensuada y responsable de práctica social, frente a las situaciones que "han decidido" les conciernen.

Se trata de que la política e intervención social, ante los desafíos aún no descifrados plenamente de una modernidad en crisis, proponga el ejercicio de levantar y descifrar la pluralidad de voces, con su potencial denunciativo y propositivo como forma de entenderlos y asumirlos; pero también, que estos discursos sean articulados a una constelación ético-teórica que contribuya a su comprensión. De tal forma que estas podrían orientarse de manera más reflexiva, compleja, flexible y cercana a los contextos, sujetos y conceptos que se enuncian y que son simbólicos, porque expresan racionalidades distintas; un sentido más cotidiano y argumentativo de "leer" la realidad.

\section{A manera de proposición}

Si se entiende que las políticas sociales se gestan en lo público, siendo una forma de intervención social institucionalizada que se origina y se hace efectiva en la sociedad, en un espacio público, entonces, intervención social y política social son una posibilidad de gestión pública que coincidirían además, en el objetivo de interpretar crítica y reflexivamente la llamada "cuestión social" contemporánea.

La propuesta es que tal interpretación y accionar parta de las enunciaciones de sus propios actores, sean estos los sujetos a quienes se dirige o los agentes 
sociales o instituciones que las direccionan, que se entiende, son "matizadas" según sus diferentes realidades socio-culturales, para que constituidas como referentes contextuales, permitan "leer" esa realidad y su articulación o no a referentes ético-teórico sociales, que conlleven a un accionar más contextualizado y complejizado desde lo público, y es que "todo lo que tiene repercusiones públicas es público y las actividades de la sociedad civil tienen repercusiones públicas" (Cortina, 2006: 4).

Este es un reconocimiento a la autoreflexividad y escucha de los propios actores, no solo acerca de sus condiciones de vida y formas de asumirla, sino además, de la forma como se autodefinen, visionan y construyen su futuro, así como del impacto que las políticas sociales han producido en ellos. Por lo que, en este tipo de política e intervención social ha de entenderse que la solidaridad y corresponsabilidad son principios no solo para la definición y práctica de unas condiciones de comunicación reflexiva mínimas, sino para la comprensión y operacionalización de propuestas según sus realidades.

Con lo anterior, se trata de asumir la participación autónoma, solidaria y corresponsable de cada actor, sujeto de derechos, como el potencial hacia el cual han de orientarse en la contemporaneidad las políticas e intervenciones sociales. En ese sentido, se habla, de una complejidad de estas, en tanto que se presente como reflexiva y flexible frente al querer ser y la cotidianidad de los sujetos a quienes se dirige, de los agentes sociales y de las entidades participantes, en un diálogo ético que permita reconocer lo identitario, lo realmente "diferenciador" de los participantes, en intervenciones sociales "diferenciadas"; sus discursos, en el marco de cada escenario socio-cultural particular en que interventor e intervenidos se encuentren como cointerventores y por lo tanto, corresponsables legítimos del diseño y ejecución de las mismas.

Un análisis discursivo de las políticas sociales en Colombia conlleva a iniciar por preguntarse si la intervención social institucionalizada a través de tales políticas, sigue teniendo por sentido el contribuir a acciones estratégicas o instrumentales que acordes con la perspectiva de impulsar su "liderazgo", terminan por potenciar individuos que se orientan más hacia el logro de su propio bienestar o del grupo que se "beneficia", que de un bienestar colectivo más amplio. Si es así, entonces cuál es el sentido que tales políticas tendrían para el mejoramiento de la situación de un país, que como Colombia evidencia problemas como la pobreza extrema, un bajo índice de desarrollo humano, la desaparición forzada, el desplazamiento forzado y la violencia a todos los 
niveles, para solo mencionar algunos, los cuales tienden a agravarse cuando el quiebre y la descomposición de los lazos sociales y comunicativos no se intentan al menos, trabajar a través de estas, evitando que siga haciendo "carrera" el uso de la fuerza y la eliminación social y hasta física del otro, como forma de resolver los conflictos sociales.

Se hace mención que el accionar de lo social en las políticas sociales ha transitado sistemáticamente por caminos dirigidos al funcionamiento del individuo en la sociedad, posibilitando que este adopte, muchas normas sociales y morales que no ha tenido la oportunidad de formular, que en otras ocasiones ha llegado a desechar, precisamente por no encontrarle sentido ni identidad consigo mismo; por lo cual, la conciencia moral erigida en cada persona como la que da razón de sus actos en la sociedad, ha sido establecida por una suerte de velada "coacción" del agente social que "interviene", como un mecanismo para acceder a ciertos beneficios que las políticas sociales ofrecen y como alternativa para superar el que estas sean asumidas por la vía de hecho.

Todo esto ha traído como consecuencia una moral vinculada a un sistema instrumental y estratégico que potencia una voluntad individualista e interesada de los participantes en tales políticas, desvirtuando el sentido de estas: potenciar acciones dirigidas esencialmente a lograr un entendimiento de las personas, a partir del fomento de la cooperación e integración social. En ese sentido, surge entonces la pregunta acerca de ¿al servicio de quién se encuentran las políticas e intervenciones sociales que de ellas se derivan? ¿al servicio de la gestión tecnocrática de las instituciones, agentes y al de la gestión de los más "vivos"? o ial servicio de todos y cada uno de los sujetos participantes en el proceso de integración social, de los más vulnerables?

Pues bien, hoy la política e intervención social ya no puede seguir teniendo como finalidad la construcción de un individuo autónomo, en el ostracismo que le da su real saber y entender, su libre albedrío para actuar, sino que los agentes profesionales que instrumentalizan las políticas sociales así como las propias instituciones, deben incluir como sentido, el contribuir al potenciamiento de personas que, a partir de un ejercicio deliberativo y dialógico en torno a sus condiciones de vida y las formas de mejorarlas, configuren un sistema normativo y regulativo de sus prácticas sociales, que sirva de base para el fomento de una sociedad más libre, pero también más igualitaria y democrática, con mayor reconocimiento y aceptación de las diferencias, y

Palobra No. 11. Septiembre de 2009 - Agosto de 2010 
donde tenga lugar un verdadero ejercicio de poder a través de la solidaridad con los "otros", quienes son prójimo, extraños y diversos, a la vez.

De esta forma, las normas y prácticas a construir por los mismos actores participantes en estas no estarían determinadas únicamente por la conciencia moral solipsista y el interés de cada uno de ellos, sino también por la participación racional discursiva de los "otros", con quienes comparte el contexto donde nace o socializa, su mundo social; como legítimos "otros", es decir, como interlocutores válidos para argumentar sus pretensiones de validez en un diálogo simétrico y fraterno, lo que hace válidos tanto los ideales e intereses propios, como también los de esos otros, para allanar el camino hacia una mayor justicia social, solidaridad y bienestar colectivo.

En ese sentido, las políticas e intervenciones sociales, se inscriben en el marco de una razón moral dialógica, que permita el reconocimiento y respeto recíproco por la dignidad de cada una de las personas, en los diferentes ámbitos de la sociedad, para un entendimiento lingüístico e intersubjetivo "sobre algo en el mundo".

El ámbito de actuación de las políticas e intervenciones sociales, debe inscribirse en el sujeto, pero también en lo que nos hace más humanos, es decir, en la comunicación y en la fraternidad con los "otros" con los que se socializa, porque aún "cuando la socialización no lo prevé todo, cuando deja a los individuos en la incertidumbre, cuando mañana les prohíbe lo que les ha hecho desear ayer, cuando no es más creíble, cuando deja de sancionar las desviaciones, cuando prescribe conductas contradictorias, cuando es impracticable..." (Bajoit, 2003: 179-180); allí cuando pareciera que tal socialización no es esencial para la reproducción de la vida de los individuos y del colectivo, es cuando más sentido tiene la revitalización de los lazos sociales, como vía para proteger a las personas y al mismo tiempo, acercar sus vínculos lingüísticos. Una de las formas de hacerlo es a partir de la reflexividad, argumentación discursiva y comprensión racional de los sujetos acerca de los nuevos caminos de actuación a elegir, donde la corresponsabilidad de cada uno de los participantes legitime los mismos, potenciando sujetos autónomos pero al mismo tiempo, solidarios frente a las mismas posibilidades que el otro también tiene.

Porque cuando la razón en una sociedad se centra únicamente en la autonomía del individuo, como un rechazo al control social, surge lo que Habermas llama "patologías en el mundo de la vida" (2000: 195), y que otros autores 


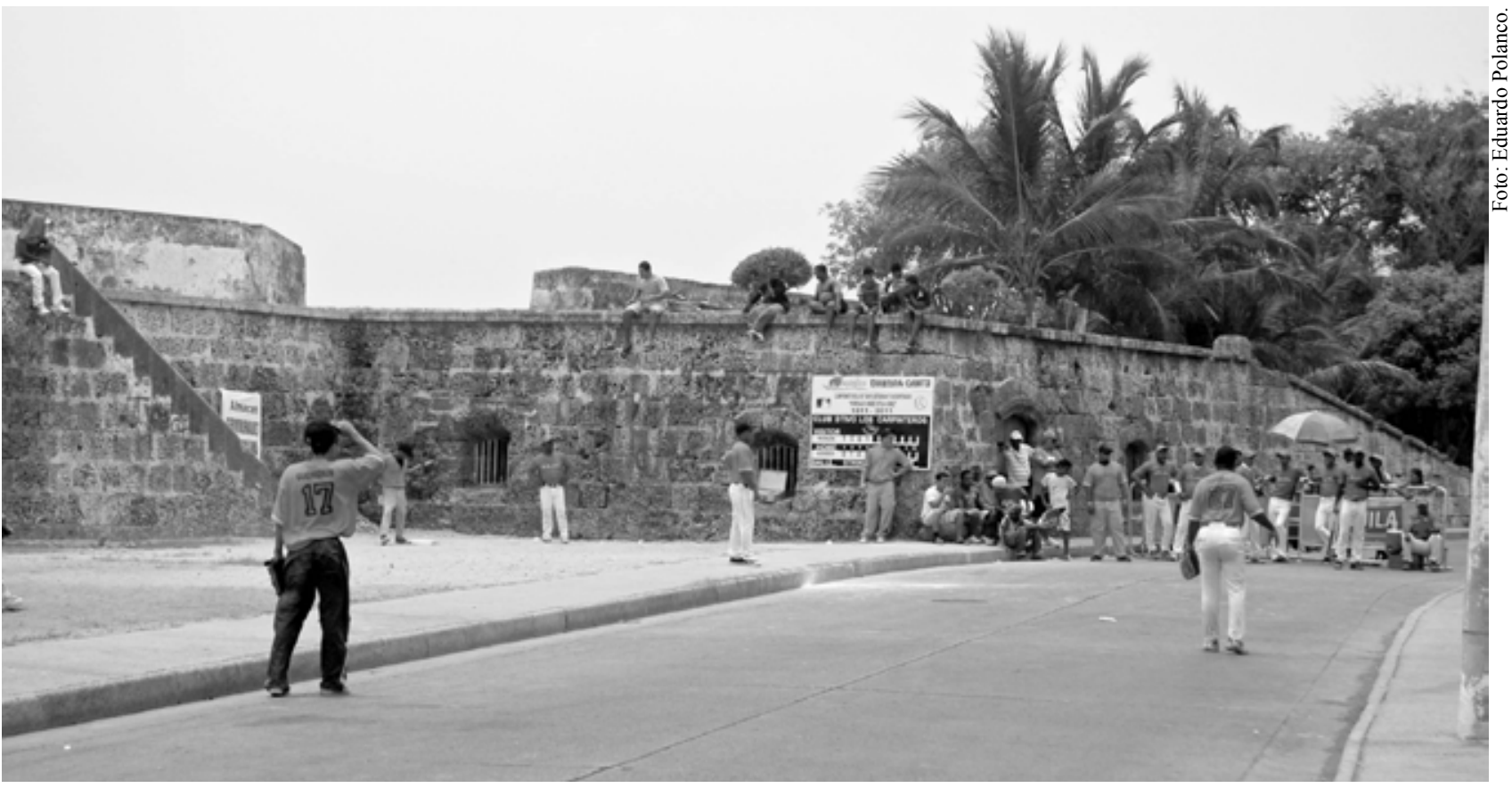

Domingo de softball. Cartagena 2011.

denominan, "trastornos relacionales" (Bajoit, op. cit); producto de la soledad, el aislamiento, la desconfianza, el evitar al otro y el conflicto porque "el olor al otro se vuelve insoportable: ya no se puede sentir" (Gauchet, 1985. En: Ibíd.: 203), produciéndose un efecto "boomerang", que devuelve al individuo su necesidad de que los demás lo reconozcan, pero también la necesidad de que reconozca a esos "otros", a fin de poder reconstruir su identidad.

Más allá de la continuación de políticas e intervenciones sociales marcadas por el fomento y fortalecimiento de las "habilidades o competencias técnicas y sociales" del individuo, hoy en día se elevan propuestas para que estas potencien el ejercicio ciudadano de las personas a partir de sus prácticas sociales, lo que implica entre otras cosas, un accionar social en "una nueva relación con la norma: en vez de una relación de interiorización fundada en el miedo de las sanciones y el gusto por las recompensas, enseñarles una competencia de gestión por lo normativo" (Ibíd.: 207), privilegiando la subjetividad, intersubjetividad y competencias comunicativas, tales como la autonomía y la solidaridad en el marco de una pragmática universal.

Y es que ante la crisis de la sociedad moderna, estas políticas deben orientarse ante todo a intervenir con las personas, para recuperar entre otros aspectos esenciales para el individuo y los diferentes grupos sociales y culturales, el sentido de la dignidad humana, el reconocimiento y respeto por todo otro 
distinto y semejante a la vez, la promoción del ejercicio de derechos de todas las generaciones y una comprensión más compleja del contexto social. Las personas más que "beneficiarios" han de ser reconocidos como unos ciudadanos sujetos de derechos y deberes, autónomos y solidarios, capaces de elegir y proponer frente a las intervenciones sociales derivadas de tales políticas.

Y es que la solidaridad, además de ser un mecanismo de integración social, es también expresión y fundamento de ciudadanía y al igual que la autonomía, al decir de Habermas, es una competencia comunicativa de las personas que se individualizan por vía de la socialización, y que en el diálogo "ocupen la misma posición en la relación, que participen de la misma identidad colectiva..." (Ibíd.: 219); porque aunque en el tema de la solidaridad, señala Bajoit tal simetría no es condición sine qua non para que esta se dé, por cuanto "puede formarse una solidaridad entre individuos que no ocupen las mismas posiciones sociales (es el caso de los altruistas, por ejemplo), como asimismo puede no formarse entre individuos que si ocupan la misma posición social (si adoptan lógicas de sujeto y de intercambio diferentes)" (ibíd.); para que esta propuesta tenga verdadero sentido de reconstrucción del vínculo social desde el diálogo, es necesario que las políticas sociales no contribuyan a lo que Autés llama un "tratamiento desigualitario" (op. cit.: 49) o lo que para Castel es una "atribución de un estatuto especial a ciertas categorías de población" (2004: 69), conocido como "discriminación positiva", y que implica una movilización extraordinaria de cierta cantidad de recursos sobre poblaciones específicas (ibíd.:73); por cuanto la desigualdad sigue su camino pues la estigmatización toma entonces una huella más indeleble tanto para el sujeto como para la sociedad, pues "desde el momento en que se comienza a asignar un estigma a este tipo de situaciones, cabe temer formas de exclusión a través del encierro, no en un espacio vallado, sino en una etiqueta que discrimina negativamente a las personas a las que se aplica cuando, en realidad, dicha etiqueta querría discriminarlas positivamente" (ibíd.: 69); por lo tanto se sigue asumiendo al sujeto como desigual con relación al agente social, a la institución, lo que hace que este no cobre mayor autonomía en la relación establecida en el ámbito de estas políticas e intervenciones y la solidaridad tenga más un carácter filantrópico.

En el caso de Colombia, esto sucede por ejemplo, con las personas que han sido llamadas "desplazados", "desmovilizados", "madres cabeza de familia", "pandilleros", "adolescentes embarazadas", su condición no se pierde nunca para el imaginario social, aún a pesar que en algunos casos, la política dirigida 
a ellos, sea temporal. En ese sentido, no se trata de una oposición frente al "dar un poco más a los que tienen menos", esto es necesario; el tema es que el tipo de "dispositivos" ofrecidos han de ser transitorios y no permanentes, dirigidos a superar tal vez el momento más difícil de estos actores, pues lo permanente debe ser el reconocimiento de su condición como "iguales" para expresarse y la apertura de espacios cada vez más amplios y creativos para "levantar" sus demandas sociales, porque esto también es una muestra contundente de solidaridad y corresponsabilidad por parte de quienes agencian las políticas e intervenciones sociales, al reconocer que son tal vez "excluidos" pero provisoriamente.

Se entiende entonces, que la política e intervención social derivada de esta, ha de orientarse hacia el fomento de relaciones dialógicas simétricas, serias y honestas, entre sus participantes; que implica su corresponsabilidad y compromiso hacia la individualización de cada persona, pero también para que esta asuma un sentido de colectividad, a partir de una solidaridad virtuosa de y hacia los demás con quienes interactúa en ese ámbito racional, argumentativo y discursivo en que se convierte tal intervención, y evitar el aprovechamiento sistemático de ventajas por parte de unos pocos, en nombre de situaciones sociales desafortunadas e identitarias compartidas.

Es decir, que el interés por la autorrealización individual se conserva, pero este pasa por la reflexividad individual y colectiva de un ideal de sociedad construido dialógicamente. Ello implica la comprensión de los intereses que esgrimen con carácter de universalización en sus discursos argumentativos, todos cuantos interactúan y resultan afectados por los problemas derivados de la aplicación o administración de las normas prácticas válidas por consenso.

Para esto, los interlocutores parten por enunciar las condiciones ideales que guiarán la comunicación fáctica, las cuales han de orientarse al logro de un acuerdo racional sobre las pretensiones de validez de los participantes dejando que al final, sea la fuerza del mejor argumento, el que según los actores exprese más auténticamente el interés general de todos los participantes o representados (que no debe ser distinto a aquel que pretenda lo que ellos determinen como sus ideales de justicia social y bienestar colectivo), producto de la deliberación, escogencia y cumplimiento de normas de actuación para todos los actores participantes en el marco de las políticas sociales y su accionar. 
Tales normas pueden seguir siendo revisadas cada vez que se susciten nuevas situaciones y actores. Y es que siguiendo a Habermas, el carácter éticodialógico en la política e intervención social implicaría que incluso, "una persona beneficiaria tiene que tener la oportunidad de decir no" (2001: 117).

Por ello se entiende que tal política e intervención social es de doble vía, pues "intervenir significa actuar voluntariamente, hacer uso de las competencias propias, del propio saber y hacer" (De Robertis, op. cit.: 156), pero también es reconocer, esperar e impulsar que los demás también lo hagan, porque hoy sus participantes más que "beneficiarios", son sujetos de derechos, ciudadanos, y por lo tanto iguales, en el diálogo y en la acción, que en este caso, usualmente han sido asumidos como "necesitados" o "carenciados" y por lo tanto, como desiguales en el accionar inicial y final de las políticas sociales.

Ha de reconocerse que las personas son seres individuales pero también colectivos y en esa medida, lo que tal accionar debe buscar es promover con ellos, el "empoderamiento" de su propia vida y su integración participativa en la sociedad, lo que De Robertis llama "acceso a la ciudadanía" (ibíd.: 71). Lo anterior implicará entre otras cosas, que se piensen y resignifiquen las representaciones e imaginarios de poder que permanecen implícitos en las políticas e intervenciones sociales, dado el autoritarismo con que las instituciones y sus agentes actúan en muchos casos, basado en el manejo de los recursos y la "experticia" ganada en este ámbito, a lo largo del tiempo.

Se trata de generar procesos para traer a la conciencia los determinantes de una forma concreta de estar estructurada la realidad social, deshaciendo sus poderes represivos sobre la razón, o lo que es lo mismo, fomentando la capacidad de argumentación racional del sujeto sobre sí mismo y sobre la sociedad. Lo que posibilita que todos los afectados por determinadas situaciones sociales puedan "erigir pretensiones de validez en sus actos de habla y difundirlas y defenderlas discursivamente. Reconocerle tal derecho, significa asumirlo como persona, legitimada para participar activamente -o ser tenida efectivamente en cuenta- en los diálogos cuyos resultados los afecten sin que exista justificación trascendental alguna para excluirlos de ellos o limitar sus intervenciones en comparación con otras personas" (Salvat, 2002: 150).

Con este enfoque de las políticas e intervenciones sociales, es posible contribuir a realizar una comprensión compleja de las pérdidas en que incurre la razón y sus riesgos conducentes hacia las formas instrumentales y estratégicas, y 
en último término, del abandono y olvido de la subjetividad y más aún, de la intersubjetividad y de una racionalidad "sensible", nacida en el diálogo, como mecanismo de reconocimiento de diferencias. Este reconocimiento es la acción mediante la cual la política e intervención social va a entender la identidad del otrora "beneficiario", como ciudadano, sujeto social de derechos y deberes, para el que y con el que, es posible construir un futuro más libre, igualitario y fraterno.

Este carácter ético-discursivo-procedimental perfila las políticas e intervenciones sociales a un accionar orientado más hacia el entendimiento intersubjetivo a partir del diálogo, que al éxito en el logro de fines, tanto propios del agente que interviene (ya sea instituciones o profesionales vinculados a éstos), como de los sujetos "intervenidos"; mediante acciones instrumentales o estratégicas dirigidas y sustentadas en una suerte de "pedagogía del éxito y el refuerzo positivo para romper la pasividad, el inmovilismo o la resignación de personas confinadas demasiado tiempo en situaciones que ellas consideran sin salida" (De Robertis, op. cit.: 79), y cuyos resultados medirán su eficacia y eficiencia. Se propone entonces, políticas e intervenciones sociales más sustentables, integradoras y corresponsables, en tanto sean consensuadas o acordadas.

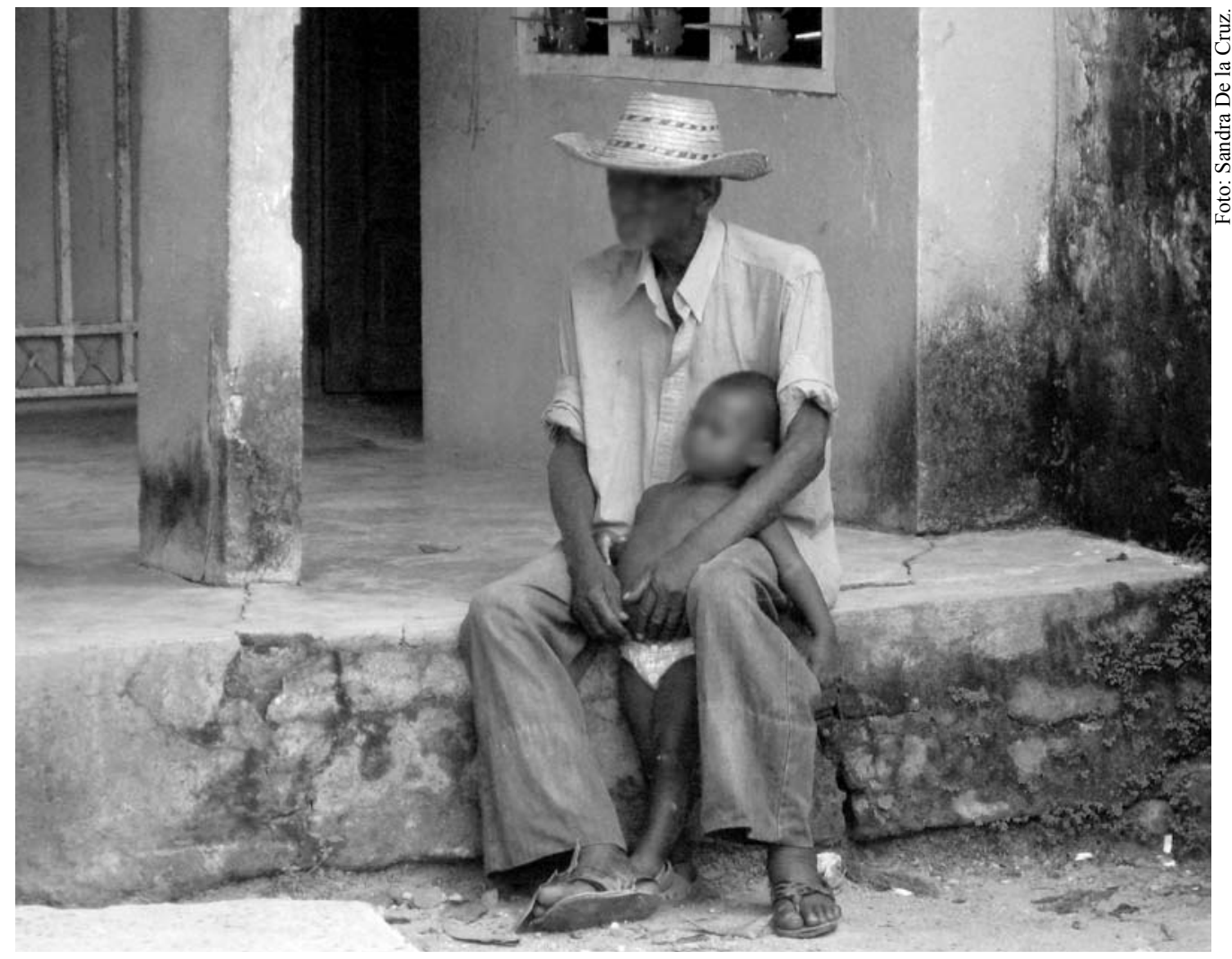

Generaciones Palenqueras. Cartagena 2011.

Palobra No. 11. Septiembre de 2009 - Agosto de 2010 
${ }^{1}$ Según Habermas, "la autonomía es más bien una conquista precaria de las existencias finitas, existencias que sólo teniendo presente su fragilidad física y su dependencia social pueden obtener algo así como 'fuerzas'" (2001: 52)
Desde esta perspectiva, una intervención o política social orientada hacia la subjetividad, intersubjetividad y autonomía como competencia comunicativa de sus participantes, versa sobre líneas teórico-conceptuales que ponen de presente una autonomía que reconoce su fundamento y origen en la socialización, en la interacción social, en el vínculo entre todos los participantes de una colectividad, desde una "inclusión del otro", como legítimo otro en el diálogo, como argumentador de pretensiones de validez, frente a una realidad condicionada social, cultural e históricamente, llegando a plantear propuestas reconstructivas de la sociedad, que potencien no sólo los ideales modernos de libertad e igualdad, sino también de solidaridad, hacia la búsqueda de un entendimiento comunicativo, sustentado en los principios de justicia social y bienestar colectivo para una convivencia pacífica, de manera tal, que pretenda "hacer llegar a la palabra a quienes se les ha excluido, a los "otros(as)" que se les ha condenado al silencio, a quienes se les usurpa la palabra, a quienes no se les abren los espacios de la comunicación" (Valencia, 2004: 63).

Lo que se propone para la política e intervención social resulta ser no solo su "ontologización" mediante el lenguaje y el ser, sino además, la búsqueda de la fuerza de su acción en la sociedad, en el intercambio recíproco entre los sujetos a partir de un diálogo racional y argumentado, de los discursos, del contenido relacional de lo que allí expresan las personas con quienes se interviene, para una mayor legitimidad de las mismas. De allí que se considere que este accionar tendrá un mayor "plus", en tanto sea mayormente potenciado desde un enfoque ético, que en este caso se propone, que funde su razón en el respeto y reconocimiento de las personas como ciudadanos, sujetos de derechos, autónomos ${ }^{1}$, corresponsables y con idéntica capacidad de lenguaje y de acción como los demás participantes de este ámbito social.

Esta, es otra lógica para la actuación de los sujetos en los diferentes ámbitos de la sociedad actual, marcada por situaciones derivadas de la globalización ante las cuales, estos tienen como reto construir un diálogo sincero y honesto con los "otros", los contenidos morales de una actuación autónoma, pero al mismo tiempo solidaria, comprensiva y corresponsable con la historia y la sociedad, que se dirige hacia el beneficio colectivo, consensuado y que busca finalmente, atenuar tales efectos. Podría proponerse entonces, que cada actor se asuma como un "...defensor de los derechos humanos, a la vez solidario y lúdico, altruista y hedonista, que no rechaza la mundialización pero que exige "otra", cuyo contenido no está inventado" (Bajoit, op. cit.: 276). 
Hoy, una política e intervención social, asumida desde esta perspectiva del potenciamiento de la subjetividad, intersubjetividad y autonomía en países como Colombia, tendría sentido como dispositivo para contrarrestar los efectos de la inequitativa distribución de la riqueza, la desigualdad social y la violencia, contribuyendo al fomento de la libertad de expresión frente a las situaciones que viven y atemorizan a casi todos, así como a superar la indiferencia frente al dolor y el sufrimiento de los demás y evitar el silencio de quienes callan por temor.

Esta es al mismo tiempo, una forma de contribuir solidariamente a potenciar las redes sociales para mejorar las condiciones de ese mundo vital compartido intersubjetivamente, y donde cabe a todos y cada uno, la responsabilidad de hacer una historia diferente, ya sea como participantes o como agentes o instituciones que implementan la intervención social derivada de las políticas sociales. Es una propuesta para las políticas e intervenciones sociales, con una lógica asociada a la reflexividad, la argumentación, el discurso, la solidaridad y la corresponsabilidad con la sociedad y la historia.

Frente a este enfoque propuesto habrá sin duda muchas más cosas que decir, y en el caso colombiano es posible pensar que como señala Autès: "hay problemas tan complicados que, si se permite a los ciudadanos expresarse, se desatarán debates peligrosos, arriesgados. Pues bien, no veo como evitarlo. Al ciudadano hay que educarlo, hay que instalar espacios públicos en los que, como dice Habermas, cada cual tenga el derecho de hacer valer sus pretensiones de validez. Entonces, si el juego se juega correctamente, el que dice estupideces debe renunciar a ellas y adherirse a argumentos o enunciados más verdaderos, más justos y más auténticos. Se acusa a este esquema de ser particularmente utópico e idealista, pero es el único que corresponde a lo que es el ideal de una sociedad democrática" (2004: 49-50).

\section{BIBLIOGRAFÍA}

AuTÈS, Michel. 2004. Tres formas de desligadura. En La exclusión: bordeando sus fronteras. Karsz, Saül (coord.). Barcelona: Editorial Gedisa. Págs 15-53.

BAJOIT, Guy. 2003. Todo cambia. Análisis sociológico del cambio social y cultural en las sociedades contemporáneas. Colección Escafandra. Santiago de Chile: LOM ediciones.

CASTEL, Robert. 2004. Encuadre de la exclusión. En La exclusión: bordeando sus fronteras, coord. Karsz, Saül (coord..). Barcelona: Editorial Gedisa. Págs. 55-86.

Palobra No. 11. Septiembre de 2009 - Agosto de 2010 
CORTINA, Adela. 2006. Ética pública desde una perspectiva dialógica. Memorias $33^{\circ}$ Congreso Mundial de Escuelas de Trabajo Social. Santiago de Chile. Agosto 30 - Septiembre 2.

DE ROBERTIS, Cristina. 2003. Fundamentos del Trabajo Social. Ética y metodología. Sevilla: Universitat de València, ED. NAU Llibres.

HABERMAS, Jürgen. 1991. Escritos sobre moralidad y eticidad. Barcelona: Editorial Paidós. . 2000. La constelación nacional: Ensayos críticos. Barcelona: Editorial Paidós. 2001. El futuro de la naturaleza humana. Barcelona: Paidós.

MATUS, Teresa. 2005. "Hacia una intervención polifónica". En Apuntes sobre intervención social. Santiago de Chile. (Paper).

SALVAT, Pablo. 2002. El porvenir de la equidad: aportaciones para un giro ético en la filosofía contemporánea. Santiago de Chile: LOM Ediciones.

VALENCIA, Harold. 2004. "El psicoanálisis bajo la mirada de Jürgen Habermas". En: Revista Unicarta 101. Cartagena: Editorial Universitaria. Págs. 59 - 64 